\title{
Empresariado turístico peruano: esbozo de una tipología
}

\author{
Sonia Tello Rozas \\ Lourdes Milagrito Alegría La Rosa*
}

\begin{abstract}
Introducción
El análisis del turismo como práctica social y económica de ninguna manera puede ignorar al turista quien, con su desplazamiento, origina una serie de actividades productivas; su participación es fundamental, sin él no hay la posibilidad de generar servicios turísticos ${ }^{1}$. Sin embargo, y tomando en cuenta que el notable incremento en el movimiento de turistas registrado durante el último siglo no hubiera sido posible sin el desarrollo paralelo de servicios básicos y complementarios, consideramos que el estudio de las organizaciones que los producen es no menos importante. En este sentido, lamentamos la falta de investigaciones que indaguen por las características y razones del accionar de las empresas en el ámbito turístico, tema que cobra mayor relevancia en el contexto peruano dado el potencial en recursos aún no explorados, las pers-
\end{abstract}

\footnotetext{
Se contó con la colaboración de Natalia lju. Fabiola Signori y Maria Eugenia Goiburu asistentes del Instituto de Investigación de la Excueja de Turismo y Heselería de la Unjversidad de San Martín de Porres.

I Regina Schluter. Inrestigación en mrismo y hoteleria, Centro de Investigación y Estudios Turisticos. Buenos Aires, 2(Kk): 137.
}

pectivas de crecimiento tanto de flujos como de inversión, la reducida presencia de empresas capaces de crear valor añadido o de generar novedosos productos y el insuficiente protagonismo de la empresa privada en el campo del turismo.

El interés de la investigación que presentamos reside en acercarnos a las prácticas empresariales a través del análisis de la unidad de producción que genera los bienes y servicios adquiridos por el turista en el contexto específico peruano; tarea nada fácil si tomamos en consideración que la actividad turística engloba muchas otras actividades económicas. Más complejo aún es el intento de identificar las características y explicar el accionar del agente económico encargado de producir lo que el mercado turístico requiere. ¿Cómo definir al empresario turísti$\mathrm{co}$ ? ¿Es éste el prestador de servicios de alojamiento? ¿Aquel que invierte en el negocio de transporte aéreo, de alimentación, de elaboración de paquetes turísticos o venta de boletos? ¿Es el artesano, que emprende su actividad comercial con el fin de producir recuerdos visibles del viaje? 


\section{Múltiples empresas, una actividad}

"Empresa turística es aquella organización social, estructurada en niveles de mando y funciones, que invirtiendo capital tiene como fin produciry prestar unos servicios para posterior comercialización y venta en el mercado, con el último fin de obtener un beneficio"2 .

Con Montaner, muchos de los autores que en los últimos años han centrado su análisis en temas relativos a la economía del turismo y al mercado turístico ${ }^{3}$ coinciden en afirmar que la empresa turística, a pesar de ser un tipo de organización con características propias, es ante todo una empresa, por tal motivo se aplican a ella todos los conceptos generales sobre el tema. No obstante, para el análisis de ella y del empresario turístico, se torna indispensable hacer algunas salvedades.

La primera es que la empresa turística, a diferencia de organizaciones que se desarrollan en otras actividades productivas, no constituye una unidad funcional en sí misma ${ }^{4}$. Para satisfacer las necesidades de los clientes-turistas son puestas en relación distintas acciones que comprometen diversos campos de la actividad empresarial. Tal como afirma la Organización Mundial del Turismo son la hostelería, el transporte y las industrias de viaje los tres pilares que sustentan la realización de esta actividad, sin embargo cada uno de ellos es en esencia un servicio que incluye otras prácticas empresariales ${ }^{5}$. Por otro lado, se desenvuelven alrededor del turismo actividades complementarias como la producción de artesanías, actividades culturales, actividades deportivas, cada una de las cuales persigue objetivos distintos, se realizan con una lógica diferente de producción e

\footnotetext{
Jordi Montaner. Estructura del mercalo turistico. Sintesis. Madrid. 1998: 127. Ver Manuel Figuerola, Economia para la gestión de las empresas turisticas forganiación y gestion). Centro de Estudios Ramón Areces. Madrid. 1995; Carlos Vogeler y Enrique Hernández. Estructura y Organización del Mercado Turissico, Ramón Areces. Madrid. 1999: Cristóbal Casanueva e1 al.. Organización y gestión de empresas turisticas. Pirámide. Madrid. 2 (Ko).

Regina Schlüter. op. cit.:135.

Son parte del rubro hostelero los servicies de alojamiento en sus distintas modatidade así como los servicios de alimentación (restaurantes, night clubs, bares. ekc.). Las indussrias del viaje incluyen empresas de tour operadores. agencias de viajes y clubs. En lo que se refiere a transporte. están contenidos los servicios de transporle aéreo, maritimo y terrestre. Organización Mundial del Turismo, Imoroducción al furismo, OMT. Madrid. 1998: 55
}

involucran a individuos con diversas percepciones de empresa y del turismo.

El análisis del tema en el caso peruano se dificulta aún más porque los empresarios implicados en el negocio turístico difícilmente se perciben como integrantes de una sola actividad. Prueba de ello es la existencia de diversidad de gremios empresariales que agrupan individualmente a los distintos rubros, desde asociaciones de empresarios ligados a la inversión hotelera, pasando por los que se dedican al servicio de transporte hasta agencias de viaje y tour operadores de las más diversas modalidades, todos ellos pugnando por intereses particulares (ver Anexo 1).

\section{El empresario turístico y su entorno}

En la década del 90, después de una etapa caracterizada por el papel preponderante del Estadoy la industrialización por substitución de importaciones, se inicia en el Perú un período de reformas económicas orientadas a la liberalización de mercados ${ }^{6}$. Para lograr tal fin, y como parte del proceso de ajuste estructural, el gobierno decidió eliminar los modelos empresariales que desde fines de los años 70 se mantenían vigentes. Se anunció un proceso de privatización de empresas estatales y la eliminación de trabas comerciales con la finalidad de fomentar la competencia entre empresas nacionales y extranjeras.

Las empresas productoras de bienes y prestadoras de servicios turísticos no fueron ajenas a las medidas implementadas. El proceso de privatización puesto en macha incluyó la venta de empresas públicas del sector turismo ${ }^{7}$; no obstante, en nuestro rubro, los efectos de la liberalización del mercado recién fueron visibles después de 1992 , una vez superada la epidemia del cólera y reducidos los movimientos terroristas.

Como respuesta a los estímulos dados para facilitar el ingreso de nuevas empresas en el merca-

6 John Crabisee y Jim Thomas. "Preficio", en El Perá de Fujimori: 1990 - 1998. Universidad Pacílico / IEP. Lima, 1999: I5.

7 Hasta febrero de 1997 se registra un monto de 47 millones de dólares americanos por la venta de empresas turisticas que eran de propiedad estatal. Drago Kisic. "Privatizaciones. inversiones y sostenibilidad de la economia peruana". en John Craburee y Jim Thomas, op. cit: 89 . 
do y al paulatino incremento en el flujo turístico, especialmente extranjero, se apreció un significativo crecimiento en la inversión orientada a esta actividad, casi toda ella destinada a la creación de nuevas empresas. Así, la inversión extranjera en el ramo, que en 1990 fuera de 10 millones de dólares, se incrementa a 19 millones en 1994 y a 42 millones en 1999 (ver Anexo 2).

Transcurridos más de diez años del inicio de este proceso es posible observar que son las grandes sociedades anónimas con afluencia de capital extranjero, las que lideran el mercado turístico peruano, se advierte también la presencia de cientos de pequeñas empresas de corte familiar con una escasa participación en el sector. En algunos casos esta nueva configuración empresarial ha determinado la formación de monopolios privados con las distorsiones que ello conlleva.

Asimismo, las grandes empresas turísticas, en relación con grupos de otros sectores económicos, tienen una importancia marginal. Según Webb y Fernández Baca ${ }^{8}$ en 1998 eran doce las empresas turísticas, entre hoteles y restaurantes, que figuraban en el grupo de las mil empresas líderes en el Perú, generando entre todas un ingreso que representaba sólo el 0,4\% del total de ingresos considerados (ver Anexo 3). Cabe resaltar también la concentración espacial de los grandes capitales invertidos en actividades turísticas; es el rubro hotelero un ejemplo representativo. En 1999 , de los 47 hoteles de cuatro y cinco estrellas existentes en el Perú, 37 estaban ubicados en la ciudad de Lima y los restantes dispersos en seis ciudades (ver Anexo 4).

\section{La empresa turística moderna}

En las décadas del 60 y 70, principalmente en los Estados Unidos, se produce un cambio significativo en las empresas de gran tamaño y en el papel del empresariado. A partir de un acelerado proceso de fusión iniciado en 1960 y con el objeto de lograr una efectiva gestión empresarial, la propiedad de las grandes empresas se fragmenta entre miles de pequeños empresarios ${ }^{9}$. Si bien el fe-

\footnotetext{
$x$ Richard Webb y Graciela Fernández Baca. Anuario Essadistico Perni an Nimeros
} 2(x)!), Cuánto. Lims, 2(xk) nómeno no era novedoso ${ }^{10}$, el amplio reparto de acciones dio lugar a una forma de gestión empresarial caracterizada por la separación entre la propiedad y la dirección de las empresas. En el Perú este fenómeno se aprecia de manera contundente, aunque no en las mismas dimensiones, a partir del proceso de liberalización de los mercados producido en el transcurso de los años noventa.

Conviene, entonces, hacer una clara distinción entre propietario, empresario y directivo. El primero identificado como aquella entidad o persona que aporta capital para la formación o funcionamiento de la empresa, en tanto el empresario es definido como la figura intermedia entre propietarios y directivos, caracterizado por ser "la persona que tiene la idea de la empresa y la pone en marcha"11: El directivo, considerado desde entonces pieza clave dentro de la organización, es entendido como aquel empleado de la institución que tiene el encargo de planificar, dirigir, organizar y controlar las actividades. Es necesario resaltar que en el caso de pequeñas empresas el límite entre los tres conceptos suele ser ambiguo, pues el empresario desempeña varios papeles.

Ensayistas liderados por Peter Drucker exploran a partir de este período en diversos sistemas organizacionales y propugnan nuevas formas de administración. Se intenta demostrar que la empresa moderna para ser eficiente y competitiva debe replantear sus objetivos orientándolos no sólo a generar ganancias sino y principalmente a crear clientes, es decir, convertir la demanda potencial en demanda efectiva ${ }^{12}$. Por su parte, el empresario moderno es identificado como aquél que arriesga en una institución, asume las decisiones de nivel estratégico, basa su actividad en la comercialización e innovación $n^{13}$, es capaz de generar valor, entiende la ganancia como el resultado del desempeño de su empresa y no como el fin último y que, finalmente, para alcanzar sus metas no adopta decisiones arbitrarias sino que contrata, para todos

9 A partir de entonces y por medio de la Bolsa de Valores de Nueva York se crea el llamado capitalismo popular "en el que las masas paseen una pane apreciable del capial del pais". Paul Samuelson. Curso de economia moderna, Aguilar. Madrid. 1981: 125.

10 Las grandes sociedades anónimas crecen gradualmente desde 1900 . Este crecimiento xe hace evidente durante la déada de los años veinte a través de la Bolsa de Nueva York. 1 Cristobal Casanueva y otros, op. cir: 25 .

12 Peter Drucker, La gerencia. Tarras, responsabilidades y prácticas. Ateneo, Buenos Aires. 1992

13 Según Drucker la conercialización es entendida como diseño y oferta de productos adectuados y en beneficio de les clientes. La innovación. cono la necesidad Je crear artículon o servicios mejores y más económicos, no siempre con menor valor monetario. mas si con mayor valor de uso para el consumidor. 
los niveles de la organización, gente capacitada y con amplio poder de decisión.

En el caso peruano no es difícil determinar que en las grandes empresas turísticas ${ }^{14}$, casi todas con significativa participación de capitales extranjeros o filiales de empresas extranjeras, se presenta una división entre la propiedad y la dirección. En el caso de medianas y pequeñas empresas, muchas de las cuales funcionan bajo las más tradicionales formas de organización empresarial, el empresario - propietario participa también como directivo. Además es interesante resaltar que no son pocas las organizaciones que, utilizando el róiulo de prestadoras de servicios turísticos, dedican su actividad a compra - venta de productos siendo incapaces de crear valor agregado.

Tomando en consideración estos parámetros y utilizando la tipología como técnica de análisis, intentaremos determinar el conjunto de elementos que definen y caracterizan al agente económico encargado de la producción de bienes y servicios turísticos en el ámbito peruano, así como los concernientes a la organización y al funcionamiento de las empresas.

\section{II.-Tipología del empresariado peruano}

\section{Tipos y estilos de vida}

Varias razones nos han llevado a elegir una metodología de investigación que proporcione los elementos necesarios para un primer acercamiento a la realidad empresarial en el campo de la actividad turística. Optamos por realizar entrevistas con el propósito explícito de acercarnos lo más posible a los hechos de la vida cotidiana de la empresa. Los testimonios personales tienen la ventaja de abrirnos el campo de las experiencias concretas antes de proceder al análisis más sofisticado de las prácticas sociales ${ }^{15}$. En nuestro caso, frente a la ausencia de estudios preliminares, perseguimos la idea de obtener de los propios actores las razones de sus prácticas empresariales para luego reagrupar-

\footnotetext{
14 Entre las grandes empresas se encuentran principalmente líneas aśreas y cadenas hoteleras (ver Anexos 5.6 .7 y 8 ).
}

las en distintos tipos a los que también se podría llamar estilos, con algunas salvedades. Sin ser novedosa, muy pocas veces se ha empleado esa metodología en el Perú. Conviene pues dar algunas indicaciones sobre esta manera de acercarse a las prácticas empresariales.

No hace mucho, Arellano publicó los resultados de su investigación sobre "estilos de vida en el Perú"16 y clasificó el conjunto de las prácticas socioeconómicas peruanas en nueve estilos de vida, cada uno de ellos con características propias, que resumirían la totalidad de la sociedad peruana. Claro está, la expresión "estilo de vida" es muy precaria y obedece a la preocupación de los investigadores por no otorgar a sus conclusiones el peso de una proyección larga y duradera. Por el contrario "estilo de vida" sugiere la idea de que las circunstancias socioeconómicas pueden sufrir cambios profundos y provocar la eclosión de nuevos prácticas sociales.

El caso del "tipo" que hemos adoptado para nuestro estudio es distinto del "estilo". Se inspira en la tradición de Max Weber y de sus estudios sobre la "ética protestante y los orígenes del capitalismo"17.

Aunque no ha sido nuestro propósito elaborar "el tipo ideal" o "ideal tipo" del empresario turístico peruano, lo que correspondería más a las exigencias metodológicas del sociólogo e historiador alemán, con esta primera incursión en el estudio de las prácticas empresariales hemos hecho más bien un esfuerzo para reagruparlas en torno a ciertas características a fin de obtener un panorama general de lo que ellas representan dentro del conjunto de la sociedad contemporánea. En otras palabras, hemos recogido lo que los

\footnotetext{
I5 Hornensia Muñuz y Yolanda Rodriguez utilizan similar técnica al recoger datos para su investigacion sobre el microempresariado en el Perú. Aunque el enfoque y los objetivos Jel estudio son visiblemente disimiles a los que nosotros planteamos. cabo resaltar gue las atutoras recurricron a la téenica de la entrevísta para conocer la percepción de un grupo de empresarios involucrados en actividades de pequeña escala acerca del trabajo que desempeñan y de las consecuencias de su actuar empresarial. Hortensia Muñoz; Yolanda Rodriguez, Microempresarios: Entre de mandas de reconocimiento y dilemas de responsabilidud. Instituto de Ética y Desa rrollo de la Escuela Superior Antonio Ruiz de Montoya. Lima, 1999. Vease también el trabajo en el que Enrique Vásquez, utitizando la técnica de la entrevista. recons. truye las historias empresariales de cinco de los principales grupos económicos peruanos y las emplea para explorar en las estrategias ue poder en el Pení y en el papel de los principales grupos empresariales a lo largo del sighlo XX. Enrique Vásquez. Estrategias de poder. Grupos ronsmicos en al Perí. Centro de investigación de la Universidad del Pacifico, Lima. 2000.

I6 Rulando Arellano Cueva. Los essiles de vida en el Perí. Como somos y pensanos tos perianos del siglo XXI. Consulteres y Merciados S.A. Lima. 2000.

17 Ver Rainhart Bendix. Afax Weber: An intellectual portrair, Londres, 1966: Julien Freund. Seciolegia de M/ar Weder. Peninsula. Barcelona. 1986: Anthony Giddens. Capisalis. mes y la moderna teoria social. Un analisis de los escritos de Marx. Durkheim y Max Weber, Ldea Books. Barcelona. 1998.
} 
actores nos confiaron para definir sus propias formas y maneras de ser en el ejercicio de sus funciones societales. Por lo tanto, el énfasis en nuestra búsqueda ha sido puesto en la propia visión del actor y no en los hechos que resultan de su acción en el conjunto de las prácticas socioeconómicas.

La diferencia entre "tipo" y "estilo" es notoria. El primero es más profundo y se basa en la concepción que el actor social tiene de su propia práctica, mientras el segundo es el resultado de una operación empírica basada en la lectura de los datos estadisticos. Mientras éste es cambiante y sujeto a variaciones periódicas, aquél obedece a reglas más permanentes y a fundamentos más sólidos. Porque en el "tipo" se tiene en cuenta los valores y normas que justifican la práctica social, mientras en el "estilo de vida" se recoge simplemente las señales superficiales que la expresan.

\section{Tipos de empresario turístico peruano}

Basándonos en lo planteado entendemos que existen cuatro tipos descriptivos del empresariado turístico peruano:

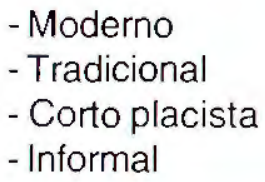

\subsection{Empresario moderno}

Para caracterizar al empresario moderno tomaremos como referencia inicial los objetivos planteados para el funcionamiento de la organización de la cual es responsable. A través de las entrevistas se pudo determinar que los propósitos del empresario moderno, como cualquier persona o entidad que arriesga capital, se orientan a la generación de ganancias. Sin embargo, en este caso específico, la obtención del máximo beneficio estará subyugada a la intención de crear nuevos productos para satisfacer su demanda:

Para mí no hay secreto, es simplemente tratar cada día de dar lo mejor de nosotros mismos, tratar de ser la mejor empresa. El lineamiento de la empresa, el perfil de nuestra empresa, el decálogo de nuestra empresa, todo eso nosotros lo tenemos con apoyo de gente. El año pasado en el mes de enero, nosotros hicimos un trabajo puntual, como si aplicásemos ISO 9000" (...)
Nosotros recibimos reportes anuales sobre la satisfacción del cliente y con satisfacción te digo, valga la redundancia, que tenemos un $98 \%$ de satisfacción del cliente (...) ellos (las agencias del exterior) $10 \mathrm{mi}$ den, yo no. Nosotros tenemos un reporte de cada pasajero que toma nuestro servicio. $(E 4: 1)$.

Bajo esta perspectiva, y siguiendo la misma lógica, el empresario moderno evidencia mediante su discurso la importancia que le atribuye al cliente, centrando en él todos sus esfuerzos:

Vender turismo, es vender servicios, se trabaja con personas, se atiende a personas y la mayor satisfacción de un operador de turismo es un pasajero (...). Obviamente somos empresarios y tenemos que ser rentables, pero no por eso nosotros tenemos que maltratar a un turista o hacer cobros indebidos o incumplir con una palabra. (E4: 2).

Cabe resaltar la importancia que el empresario moderno asigna al conocimiento asumiendo los temas de actualización y capacitación de su personal en los niveles gerenciales, directivos y operativos como una necesidad para lograr resultados positivos. Por otro lado, resalta el tema de la planificación tanto para emprender un nuevo proyecto como para mantenerlo en funcionamiento. En este sentido, compromete sus recursos a largo plazo asumiendo responsabilidades con proveedores y clientes, determina sus políticas, planifica sus inversiones e intenta establecer claramente hacia dónde orientar sus productos:

(En turismo) la rentabilidad se percibe en 3 ó 4 años, no de forma inmediata (...) pienso que hay tres factores importantes: uno proyectarse al futuro, (dos) estar adecuadamente informado del uso de las técnicas y, (tres), ser profesional cabal(E3: 1).

Yo considero que es rentable invertir en una agencia de turismo receptivo porque tiene futuro, pero la persona que invierte tiene que ser consciente del concepto de vender turismo receptivo y no sólo pensar en el retorno (...). (Hay que) tener un dinero reservado como capital de trabajo y posiblemente ni en el primer ni en el segundo año cubra sus costos. Una empresa que empieza y cree que en el corto 
plazo va a tener retorno, está equivocada. $(E 4: 3)$

A la importancia atribuida al conocimiento y la capacitación de los miembros de la organización para incrementar la productividad de la empresa, se suma el uso de tecnologías adecuadas. El empresario moderno busca y pone en práctica formas de organización y de trabajo que suministren mayor valor agregado y que demanden el menor esfuerzo:

Nosotros no podriamos estar sin tecnología. Nosotros tratamos aquí de darle el mejor uso, es decir, capacitamos a nuestro personal para que no trabaje más sino para que trabaje menos (...) y el tiempo que le queda libre lo pueda usar para ser creativo u otro tipo de cosas. (E4: 4).

Proyectarse al futuro es estar adecuadamente informado del uso de las ... hay cosas que son ajenas a nosotros (...). Estamos nosotros en el sistema por Internet, está entrando, nos está empujando entonces es muy rápido y lógicamente estamos haciendo mucho uso (de él). Hay muchísimos cambios en cuanto a la manera de operary promocionar. (E3:2)

Teniendo en cuenta el énfasis que las organizaciones modernas ponen en la satisfacción del cliente, observamos que en el caso particular del turismo se pondrá especial atención en la selección de los proveedores y los servicio por ellos prestados:

La calidad de los productos... nosotros escogemos a nuestros proveedores. Los proveedores en este caso son los lugares de hospedaje, los hoteles, los transportistas, las empresas de transporte, los guias, los trasladistas, los servicios de comida, los restaurantes y en el extranjero están los tour operadores. O sea, básicamente nosotros trabajamos o intentamos trabajar con todo este tipo de empresas de servicio que ya conocemos, que sabemos que su respuesta va a ser la adecuada y va a haber un número de quejas bajo. Si aparece un medio de hospedaje en Arequipa primero lo vamos a visitar, se va a probar cual es el producto que tiene y si está dentro o no de la calidad que exijo y de ahi se va a hacer el contrato. (E3:3).
En cuanto al papel que juega el empresario moderno en la organización, a través de los casos analizados podemos observar que el empresariopropietario desempeña también cargos directivos. No obstante se advierte que propicia la participación de los trabajadores, procurando estimular el trabajo en equipo tanto para la toma de decisiones relativas a tareas operativas como para determinar las estratégicas empresariales, intenta reunir un grupo de gente, en los diferentes niveles de su organización, con capacidad y libertad de generar nuevas ideas y de tomar decisiones:

Somos un equipo muy bien cohesionado, tenemos un equipo humano valiosísimo (...). Yo puedo estar llena de computadoras, tener el mejor sistema, todo maravilloso; pero si no tengo a las personas idóneas junto, no sirve para nada. Nosotros somos un equipo y que de por casualidad soy la cabeza; pero en determinado momento he sido la uña del dedo meñique, pero todos somos muy importantes. (E4:5).

Se hace evidente, por otro lado, la tendencia hacia una organización horizontal que de cabida a la participación activa de todos sus miembros. En ese sentido se procuran canales que hagan viable conocer las necesidades y expectativas de los trabajadores así como sus aptitudes, con el fin de lograr mejor desempeño:

Todos los de la empresa íbamos a un hotel, teníamos jornadas de todo un día con "break" y donde todos estábamos al mismo nivel, no habia gerente. Todos éramos una persona más y ante todo decidimos que éramos $X$ como empresa.

La evaluación que hicimos nos decía cuales eran nuestras aptitudes y actitudes, para qué éramos buenos, de repente estábamos en un área en la cual no podriamos desarrollarnos (...). Teníamos que hacer algunos ajustes, un ordenamiento, entonces se hizo todo un plan estratégico donde cada persona tiene como una especie de manual de funciones, pero no su manual sino orientaciones, pasos a seguir, que están estrechamente ligados con el de la compañera y con lo mío (delgerente). (E4:6).

Resulta interesante advertir la manera por medio de la cual una organización moderna busca 
que los trabajadores que forman parte de ella se identifiquen con los objetivos planteados. Gracias a las entrevistas reparamos en la importancia que se atribuye al "hacer carrera" dentro de la empresa, es decir, contratar gente con determinadas aptitudes para formarla de acuerdo a la orientación y necesidades de la organización:

(...) y luego dentro de la empresa le enseñábamos. Aquí (el practicante) pasaba seriamente por cada departamento y se le hacía una evaluación. Pero lo integrábamos a nuestra familia. A las personas buenas, buenos profesionales que llegaban pues les dijimos si les gustaría quedarse. (E4:7).

Podemos afirmar, por otro lado, que la organización emprendida y liderada por el empresario moderno atribuye mayor valor a la capacidad profesional de los miembros de la organización que al vínculo familiar. Si bien es cierto, en los casos analizados, el ingreso a la actividad empresarial se da de manera fortuita y, en muchos casos, gracias al apoyo de la familia, el empresario moderno asume el riesgo e intenta que la organización crezca y perdure en el largo plazo:

Fue una historia original diría yo. Yo estudié y mi proyecto de grado para lograr la tesis fue un hotel para turistas. Para esto por razones familiares, mi familia tenía muchos negocios, tenia la posibilidad de adquirir acciones de una empresa turístiva (...) nadie tenía tiempo en casa, entonces existía la empresa de un tío (...) un día me senté en un "counter" para mirar un poco como funcionaba y de ahi ya no salí. (E3: 4).

La participación de la empresa privada en el sistema económico es otra cuestión que cobra importancia para el empresario moderno. Éste reconoce que es ineludible el papel del Estado como regulador, encargado de establecer directivas y dotar de infraestructura básica, pero resalta también las limitaciones del sector público en el contexto de una economía de mercado y la consecuente necesidad del protagonismo privado:

Se hablaba mucho de que la 'industria sin chimeneas' genera divisas, empleos, en fin una cosa maravillosa, pero nunca se le dió la importancia que tenía. El tu- rismo es una industria que no debiera ir de brazo a la política, debiera ser apolíti$c a$, para que los funcionarios puedan permanecer en los cargos que tienen no por el aspecto económico sino un tiempo determinado para que realmente puedan concluir una labor. (E4:8).

No existe un apoyo leal de los políticos ni los gobiernos para el sector privado de turismo, para ayudar a la promoción del país, $y$ creo que esto va a continuar (...). no hay gente idónea entonces no hay continuidad. En turismo lo que se debe hacer es que el sector privado debe tomar las riendas de todo. Se están gestando muchas organizaciones no solamente gremiales, se están volviendo cada vez más activas (...) otras ONG que están tomando los papeles que le correspondería al Estado, ya que el Estado no lo hace, o si lo hace es muy esporádicamente. (E3: 5).

\subsection{Empresario tradicional}

Basándonos en los parámetros de la Teoría de la Administración y tomando como referencia las formas de organización planteadas a lo largo del siglo XX, hemos identificado a empresarios cuya experiencia empresarial se funda en prácticas heredadas, que se alejan del paradigma del empresario moderno esencialmente porque no innovan, eligiendo lo seguro y conocido. Identificamos así al empresario tradicional, como aquel que, además de basar su actividad en prácticas heredadas, considera que el éxito de la organización depende fundamentalmente del contexto y del papel que cumple el Estado.

Entre los objetivos que orientan su accionar está, por un lado, la obtención de ganancias y por otro, el mantenerse en el mercado sin necesidad de introducir cambios o mudanzas significativas en la organización. Asimismo, el empresario tradicional considera que la preparación de su personal no es una asunto fundamental en el éxito de la empresa sino un privilegio al que sólo accede el grupo de profesionales que reúna condiciones excepcionales y que, por su ubicación dentro de la empresa, tenga posibilidades de ascenso; en ese sentido tiene más importancia la experiencia que la formación profesional: 
La preparación académica te sirve como una base y la experiencia que es la madre de todas las ciencias (...) la gente que sale de cualquier instituto o cualquier universidad tiene la base, pero no la experiencia; la experiencia la hace probablemente en desempeñarse en el negocio, el trabajo de todos los días (E1:1).

La maestría definitivamente es buena, yo no digo que no, yo también he seguido un postgrado; pero en verdad en la maestría tú tienes dos años de training, dos años en los cuales estás repasando todo lo que ya estudiaste, estás afianzando tus conocimientos que los hiciste en casa veinte o treinta años atrás.. asi pienso que es ahi a donde debe dirigirse el campo de la maestría (...). Gente que realmente ya ha alcanzado un nivel en el cual se sienta satisfecha económicamente con lo que produce y con lo que gana en donde está, ese tipo de gente con una maestría puede afianzar un poco más y quizás como este caso, si tú estás trabajando en hotelería y no estás en una cadena, te permitirá meterte a una cadena y te permitirá mejorar un poco más tu nivel; pero no necesitas 100 gerentes, necesitas 1 gerente y 100 empleados. ¿Me entiendes?. (E1:2).

El empresario tradicional afirma además que la empresa se desarrollará eficientemente en la medida en la que el Estado estimule un contexto adecuado, orientado por políticas y leyes claras, y la organización se conforme por técnicos calificados que desempeñen adecuadamente su trabajo:

(...) el papel del Estado es vital, éste debe estimular que el país tenga una política definida, una manera de plantear el tema del sector con mucha inteligencia, si hay exoneración para los turistas que sea global, general, no solamente para un área de turismo organizado, sino para todo turista que llegue al pais y se pongan en conciencia las autoridades, llámese congreso, llámese del gobierno, a nivel parlamento, (...) y que realmente adecue una exoneración que realmente sea amplia y totalmente, digamos... en una forma que interese al turista a venir a este país (E1:3).

(...) lo que quiero decirte en concreto, que un curso de maestría definitivamente te da un aplomo y te da mucha más visión panorámica de la actividad o de la rama a la cual tú te dedicas, definitivamente te da, te conviertes en un empleado top, hasta cierto punto es importante, pero cuántos tops necesita el Perú en este sector también es importante ponerse a meditar, si necesitamos ahorita realmente gente top a ese nivel o necesitamos realmente técnicos bien calificados, que comiencen realmente a identificarse con el negocio como debe ser, también es importante. (E1:4).

En cuanto a la forma de organización empresarial y el tipo de empresa adoptado, observamos que el empresario tradicional optará por tipo de organización vertical en la cual el vínculo familiar tiene particular relevancia. De esta forma, el propietario-empresario juega un papel importantísimo en la estructura organizacional, asumiendo las principales responsabilidades y estableciendo las estrategias y orientaciones que guían la organización:

Yo como accionista mayoritaria, es un negocio familiar, yo trabajo con mi esposo que cubre la presidencia, yo soy gerente general, tengo a mi hijo... que es licenciado en administración, que trabaja en área de ventas, la gerencia de ventas. (E1:5).

En esta estructura de organización vertical los empleados tienen sus papeles claramente definidos y el empresario prefiere no delegar responsabilidades asumiendo tareas en todos los niveles de la organización. De esta manera el empresario tradicional es el único que adopta las decisiones y determina la misión y orientación general, a los demás miembros les corresponde ejecutar las tareas asignadas:

Es muy difícil manejar un negocio de turismo, es muy difícil, yo realmente quiero lo que hago entonces no puedo estar en mi casa descansando, de repente entra una llamada, entonces me están hablando sobre un problema o de repente me están pidiendo una 
información y yo inmediatamente estoy dispuesto a darle solución. (E1:6).

(...) me considero exitoso en el aspecto del trabajo, porque sé lo que hago y realmentela gente que me acompaña maneja la filosofía mía en la misma forma como yo sacrifico también el tiempo que doy para el trabajo (E1:7).

Otro aspecto que resulta interesante advertir es que el empresario tradicional en el ámbito turístico no considera la tecnología como un factor substancial para el éxito de su organización. Teniendo en cuenta que la actividad turística se basa fundamentalmente en la prestación de servicios, atribuye especial importancia al contacto personal que mantienen sus empleados con los clientes, el que substituiría la utilización de nuevas tecnologías:

No considero imprescindible la tecnología dentro de la actividad turística (...) el factor humano es tan importante que no es como por ejemplo como estar en USA, tú entras a una agencia de viajes, agarra la máquina la counter y te pregunta ¿qué es lo que quiere usted? Yo quiero Santo Domingo 4/3 saca su máquina, lo imprime $y$ te dice acá esta señor, y cuando el cliente pregunta más a fondo, el counter simplemente se limita a decirle lo que dice el programa,... nosotros vamos más allá de esa información somera, que es una tarifa impresa y entregada, nosotros damos un trato muy humano o sea que tú necesites Ilegar al cliente. (E1:8).

\subsection{Empresario corto placista}

El tercer tipo de empresario identificado en la investigación se caracteriza fundamentalmente por entender la empresa como un medio para hacer dinero, orientando los objetivos de la misma a la obtención de la máxima ganancia en el menor plazo. Lo hemos identificado, por este motivo, como el empresario:

La empresa nace para hacer dinero y para crear trabajo y dar trabajo y se busca un equipado económico lo más adecuado posible a las circunstancias, a la inversión (...) para hacer más ventas y ser cada vez más conocidos y obtener los resultados económicos adecuados. (E2:1).
Para lograr la máxima rentabilidad y ser competitivo en el mercado, el empresario corto placista atribuye especial importancia a los precios, es decir asume que la generación de ganancias se da a través del volumen de ventas a precios competitivos. En este sentido el Estado podría jugar un papel significativo reglamentando la política de precios y estableciendo exoneraciones tributarias para actividades vinculadas al turismo. El mismo planteamiento sería válido también en el ámbito macroeconómico, en este sentido el empresario corto placista asume que el país sería competitivo si es que se mantuviera una política de precios relativos coherentes con el contexto internacional:

Perú es considerado un país muy caro, si usted viaja a Cuzco...tres días le cuesta mucho más que un crucero en primera clase, claro no se puede comparar el turismo de un crucero con el turismo de Machu Picchu, pero la gente dice, tengo este presupuesto y quiero tomarme tantos días de descanso, entonces buscan alternativas y entre las alternativas está el crucero, está la playa, está Santo Domingo, están Islas Canarias y todo es competencia. (E2:2).

A diferencia del empresario moderno que utiliza la planificación como herramienta clave para emprender y hacer funcionar la empresa, el empresario corto placista guía su accionar por la intuición y por el placer que le pueda brindar el realizar una actividad. Arriesga capital, propio o ajeno, en aquella actividad que signifique mayores rendimientos financieros a corto plazo. En algunos casos, en el intento de aprovechar las oportunidades que se le presenten en la actividad empresarial, promueve otra iniciativa comercial sin haber finalizado una primera:

Yo entré al negocio por necesidad porque como no tenía capital, se me habia ido todo el capital, tenía que hacer algo con capital ajeno, entonces usted me da capital ajeno que yo lo trabajo (...). Me introduje en otro negocio y me apasionó el tema porque es parte del turismo (...). Me hice amigo de la familia $X$ y cambié de idea porque éste sigue siendo un buen negocio y luego (...) electrodomésticos, y ahora estoy en otro rubro, pero sigo trabajando con turistas. (E2: 3). 
Uno que hace un periódico no solamente busca ganar dinero, sino, siente que es periodista, le gusta el periodismo, el que va a vivir de la música es porque le gusta la música, lo hace bien. Asi el empresario en turismo le gusta el contacto con gente de diversos países (...), generalmente es un muy hospitalario o un buen gastrónomo (E2:4).

En lo referente al manejo de la organización, el empresario corto placista enfatiza la necesidad de rodearse de profesionales competentes para conseguir mayores ventas y por ende mayores ganancias. Sin embargo, da muestra de ser un empresario individualista que centraliza la toma de decisiones y asigna, a los demás miembros de la organización, labores puntuales:

... todo nuestro personal está constituido por profesionales, arquitectos, ingenieros, abogados o economistas, todos son profesionales que pueden dar un consejo adecuado al cliente". (E2: 5).

Como se dice yo mismo soy. Soy todo por ahora, lo que pasa es que mis hijos ya no están en el Perú (...) ya emigraron a otros países. Son mis colaboradores a quienes estoy tratando de incentivar para que sepan tomar el mando....vamos a ver si lo $\operatorname{logran}(E 2: 6)$.

Otro rasgo que identifica al empresario corto placista es la importancia atribuida a la relación de la empresa con entidades e instituciones de notoriedad y solidez financiera con el fin de lograr una imagen atractiva a quienes demandan sus productos:

Los grandes núcleos van a venir probable mente siempre a través de las grandes empresas (...) con los buffettes de abogados que están amarrados a un gran estudio de abogados en París (...). La empresa General Motors utilizará la misma empresa de publicidad en Estados Unidos (...). Así, en la actividad turística se trabaja con empresas grandes y de prestigio porque da mayorgarantía a sus clientes. (E2:7).

Este rasgo se hace evidente también en el ámbito personal, el empresario corto placista considera fundamental establecer relaciones sociales con personas reconocidas en el ámbito social, empresarial y político, por tal motivo es miembro de diversas asociaciones y participa de ellas activamente.

En lo que respecta a la participación del Estado en el mercado turístico, el empresario corto placista resalta su papel como encargado de reglamentar y vigilar el buen funcionamiento del mercado, mas no como protagonista, papel que en una economía de mercado le corresponde al sector privado:

En los países donde hay más turismo esa reglamentación (con respecto a las exoneraciones de impuestos) está bien clara, el IVA es devuelto hasta para comprar una corbata, no ahora sino desde hace veinte años, uno iba a Harrods o a cualquier tienda a compra un par de corbatas y el IGV o el IVA, según como se llame, se retornaba, porque es considerado una exportación y la exportación no se penaliza, al contrario se incentiva $y$ este incentivo aquí todavía no existe porque las autoridades tienen miedo de que alguien le saque la vuelta, bueno y qué importa si alguien les saca la vuelta, lo importante es el grueso, lo mismo los bancos no prestarían dinero porque a lo mejor alguien no paga, entonces no existirian bancos. (E2: 8).

\subsection{Empresario informal ${ }^{18}$}

La cuarta categoría relativa al empresariado se aleja significativamente de las definiciones de empresario que comúnmente se encuentran en manuales de administración. El empresario que hemos identificado como informal se caracteriza fundamentalmente por orientar los objetivos de la organización por instinto hacia la satisfacción de las necesidades de una demanda inmediata apartándose de la racionalidad empresarial de generar beneficios y crear clientes. Inicia su actividad comercial

\footnotetext{
18 La acepción informal, para este estudio, no hace alución al régimen juridico de la empresa (si está o no formalmente constituida) como tampoco a resultados financieros (que logre mayor o menor rentabilidad que otras). Utilizamos el témino "informal" a partir de la percepción que pueda tener el empresario con rélación al funcionamiento de su organización.
} 
de manera fortuita y sin planificación y responde a la demanda de sus clientes según ésta se presente, sin que ello signifique necesariamente la maximización de sus ganancias o la prestación de un servicio de calidad:

Fue una cuestión digamos fortuita, muchas de las cosas considero yo que en el Perú se empiezan asi muy informales y en el camino nos vamos formalizando. Me iban preguntando si alquilábamos habitaciones, en tonces eso nos motivó. Frecuentemente iba la gente para preguntar por alquiler de habitaciones, eso nos motivó a alquilar lo que teniamos, o sea que era nuestra vivienda y con el tiempo ya fuimos construyendo habitaciones, ya de acuerdo a las normas que daba el MITINCl, (...) poco a poco fuimos creciendo. Prácticamente hemos empezado de cero, ahora estamos con veintiséis habitaciones y aparte que yo tengo una profesión (...). Yo armo todo, o sea si quiero algo adicional como un guía tengo una sobrina que también entiende y domina un poco, además conoce la zona, y si son grupos más grandes llamo a los muchachos que trabajan. (E5: 1).

Este tipo de empresa, como en el caso del empresario tradicional, es familiar y para su funcionamiento prevalece este vínculo, así como el amical, por encima de la capacidad profesional. El empresario informal atribuye el éxito y crecimiento de su empresa al hecho de que los miembros de la familia participen activamente en ella.

Lo que yo tengo es una cosa muy familiar. En ese tiempo intervinimos tres personas, no? Tres personas que realmente combinamos, que te digo, mi apreciación actual. (...). Ninguno de mis hijos trabaja conmigo para mi desgracia. (...). Al principio mi hijo mayor, sí colaboraba conmigo, pero tiene otras (cosas), de repente no le gustó, (...) el ambiente. Me gustaría que cada uno (de mis hijos) hiciera una labor, ¿no? Yo creo que si fuera asi tendríamos la posibilidad de desarrollarnos cada vez más. (E5: 2).

Yo la gente que tengo la tengo años. Una señora que era mi empleada, me venía a lavar hace años ya como doce o quince años, entonces, un día, conversando le digo (...) le digo porqué no te vas a "X". Mi único problema es no tener dónde te quedes a dormir, pues no tengo un cuarto, no tengo espacio y ella me comenta que su mamá es de una ciudad cercana y que podía ir. Entonces me la llevé (...) ahora lava, plancha, cocina. Se quedó allá, ya con ella tenemos doce años. (E5: 3).

El empresario informal asume las decisiones en todos los niveles de la organización, es decir, determina las medidas relativas a las metas y orientación de la empresa como también las políticas a seguir en las distintas áreas.

La carencia de planificación para la puesta en marcha y funcionamiento de la empresa se refleja claramente en la política para la contratación de personal. El empresario informal selecciona y contrata empleados según se incremente la demanda y por ende la necesidad de mano de obra, evitando de esa manera establecer vínculos laborales. Evidencia mayor preocupación por el incremento en los costos y consecuente disminución de los beneficios, que por la productividad de la mano de obra:

Este año he tomado un chico nuevo que, hemos tenido que estar enseñándole poco a poco. Y hay que enseñarle los días que no hay trabajo. Poco a poco y ahora no puedo estar tampoco contratándolo para todo el mes de acuerdo a las necesidades. (...) día trabajado, día pagado, tiene su día de descanso, ellos mismos escogen, pero ese día no se los pago. Esta chiquita que te digo que es nueva solamente la llamo los días viernes, sábados y domingos, los días que hay más trabajo. (E5:4).

El individualismo en cuanto al manejo de la empresa se muestra también en el enfoque e importancia que el empresario informal presta a la preparación profesional y capacitación de los miembros de su organización. Resalta la importancia del conocimiento y de la continua capacitación personal, sin embargo, asume que la necesidad de lograr un grupo humano con un alto nivel de preparación profesional se restringe a los mandos directivos, es decir, a él y a su entorno familiar: 
Sí, allá no hay gente capacitada entonces tengo que capacitarlas en el camino. Hay mucha gente que se va a ofrecer cuando empieza la temporada para pedir trabajo. En nuestro caso, nosotros ya no podemos estar perdiendo el tiempo porque pierdes tiempo en enseñar, gente que no sabe nada, gente que va a pedir trabajo. Por ejemplo cómo le voy a dar trabajo a una persona que ni siquiera tiene un baño, que ellos no lo saben utilizar, entonces menos lo saben limpiar. Yo he tenido esos casos (...). Insisto en la capacitación. Hay muchachos bien intencionados en quedarse en el ambiente del turismo, pero no están capacitados para ello (...). Es necesario capacitación para los servidores turísticos como parte de (la labor) de los gobiernos locales. (E5:5).

En lo que atañe a la relación de deberían existir entre el sector público y el sector privado, el empresario informal atribuye un papel fundamental al Estado como responsable del crecimiento económico de la zona en la que su organización está localizada, como también para lograr un adecuado funcionamiento y resultados positivos de las empresas que invirtieron en la misma. Resalta el papel del Estado incluso en temas relativos a la capacitación de personal especializado y asevera que el éxito empresarial depende en gran medida del desempeño del gobierno de turno:

La falta de desarrollo del gobierno local, no preocuparse por un desarrollo integral de la zona imposibilita que todos puedan desarrollarse (...). Yo insisto en trabajar con los gobiernos locales, ¿no? O sea, para promoción, promocionar la zona y que no esperamos que sea algunas temporadas, sino todo el año. Porque hay atractivos para todo el año que se pueden aprovechar. Pero esto es por la falta de desarrollo de los gobiernos locales. (E5:6),

Bueno (la ciudad) ha mejorado. Ha mejorado como te digo por iniciativa del alcalde que trata de incorporar a los mismos establecimientos que dan hospedaje a que se adecúen o que también de alguna forma se capaciten; o mantener una línea de lo que es restaurantes, no vender muy caros los platos, tener la limpieza, ciertas normas que tenemos que acatar todos (E5:7).

Por otro lado, aunque el empresario informal orienta su producción a los requerimientos de una demanda insatisfecha, no se interesa por generar nueva demanda, nuevos clientes:

Los clientes llegan a mi establecimiento por que esta ciudad tiene su página web. Después por recomendación, la mayoría por recomendación. El que llega por (esta ciudad) es el que va a Machu Picchu o el que regresa de Machu Picchu, o está por volar (...). Unos me dicen (que tuvieron referencia del establecimiento por) las páginas amarillas de Telefónica, otros en la página web, otros por recomendación. (E5:8).

En cuanto a la competencia, el empresario informal muestra cierta cautela y pasividad frente a la presencia de otras empresas en el mercado. Dada sus limitaciones en cuanto innovación y creación de nuevos productos, considera la incursión de otras empresas como un factor que restringe su capacidad de desarrollo:

Quizás también la competencia ha hecho mucho. De que nosotros ya no tengamos la cantidad de gente que teniamos antes, bastante competencia, hay demasiada oferta cada año. (E5:9).

\section{Conclusión}

El turismo es, sin duda, la "actividad de las actividades". Su desarrollo conlleva la realización de diversas prácticas económicas y la conjunción en el mismo mercado de una heterogénea gama de empresas. Por este motivo, cualquier análisis relativo a la oferta turística, además de considerar aspectos relativos a los atractivos y recursos turísticos, deberá tener en cuenta las particularidades de las organizaciones que en ella participan.

El estudio realizado indaga por el fenómeno empresarial a partir de la percepción que tienen de su actividad los propios actores, los empresarios peruanos que orientan su accionar a la producción de bienes o prestación de servicios turísticos. La técnica de análisis utilizada nos ha 
permitido agrupar en categorías y determinar las diferencias entre empresarios que hacen parte de la misma actividad, así como identificar elementos comunes que perfilan las características del empresario turístico peruano.

Siguiendo la lógica de los gurús del management, podríamos afirmar que el empresario moderno emprende y desarrolla su actividad comercial, no con el sentido utilitario de maximizar las ganancias, sino dando prioridad al cliente y a la satisfacción de sus necesidades; encuentra en la tecnología una vía indispensable para incrementar la productividad y la eficiencia de sus trabajadores; se rodea de personal idóneo para alcanzar sus metas y comparte con ellos los objetivos de la empresa, delegando responsabilidades y proporcionando una activa participación incluso en la toma de decisiones.

El tradicional, heredero de una práctica familiar, pretende con el desarrollo de su actividad mantenerse vigente en el mercado, sin miras a lograr productos o servicios innovadores. Para él la tecnología es un elemento complementario, mas no indispensable en el desarrollo de su actividad productiva, siendo el factor humano el componente más importante. En cuanto a la toma de decisiones, son el empresario y su entorno más próximo los responsables por el manejo y las decisiones empresariales, cabe al resto de los miembros de la organización el cumplimiento de tareas operativas.

Por su lado, el empresario corto placista pone énfasis en la generación de ganancias en el período más breve posible, evidenciando cierta rigidez en el manejo de la organización que dirige. Como en el caso del empresario tradicional, es el propietario - empresario el que toma laś decisiones fundamentales para el funcionamiento de la institución.

La cuarta categoría identificada, el empresario informal, es raramente contemplada en manuales de administración y de marketing ya que se aleja del esquema que éstos desarrollan. El empresario informal desarrolla su actividad productiva con el fin de crear productos y servicios para satisfacer una demanda inmediata. Así, la planificación es un elemento al margen del cual toma las decisiones empresariales.

Se advierte, en los cuatro tipos de empresarios identificados, que el empresario - propietario desempeña también cargos directivos o gerenciales. La distinción se encuentra en el grado de intervención que éste tiene en la toma de decisiones en cada uno de los niveles de la organización.

Sonia Tello

Facultad de Turismo - Universidad de San Martín de Porres stello@fccsmp.edu.pe

Lourdes Milagrito Alegría Instituto de Investigación - Universidad de San Martín de Porres 


\section{BIBLIOGRAFÍA}

ARELLANO, Alejandro

2000 Los estilos de vida en el Perú. Cómo somos y pensamos los peruanos del siglo $X X I$,Consumidores y mercados S.A., Lima.

CABTREE, John; THOMAS, Jim

1998 El Perú de Fujimori: 1990 - 1998, Universi dad del Pacífico/ IEP, Lima.

BENDIX, Reinhart

1966 Max Weber. An intellectual portrait, Londres.

CASANUEVA, Cristóbal y otros

1998 Organización y gestión de empresas turísticas, Pirámide, Madrid.

DRUCKER, Peter

1992 La gerencia. Tareas, responsabilidades y prácticas, El Ateneo, Buenos Aires.

FIGUEROLA, Manuel

1995 Economía para la gestión de las empresas turísticas (organización y gestión), Centro de Estudios Ramón Areces, Madrid.

\section{GIDDENS, Anthony}

1998 Capitalismo y la moderna teoría social. Un análisis en los escritos de Marx, Durkheim y Max Weber, Idea Books, Barcelona.

FREUND, Julien

1986 Sociología de Max Weber, Península, Barcelona.

GALVAN, Liliana

2001 Creatividad para el cambio, UPC, Lima.

MOLINA CARMONA, Miguel

1998 Factores determinantes de la excelencia empresarial, Diputación de Alicante, Alicante.

MONTANER, Jordi

1998 Estructura del mercado turístico, Síntesis, Madrid.
MUÑOZ, Hortensia; RODRÍGUEZ, Yolanda

1999 Microempresarios: Entre demandas de reconocimiento y dilemas de responsabilidad, Instituto de Etica y Desarrollo de la Escuela Superior Antonio Ruiz de Montoya, Lima

\section{ORGANIZACIÓN MUNDIAL DEL TURISMO}

1998 Introducción al turismo, OMT, Madrid.

\section{PERÚ MONITOR}

1998 Los 2000 del 2000. Las empresas líderes del Perú, Perú Monitor, Lima.

PERU REPORTING

1998 Peru: the top 5400 companies, The Peru Report, Lima.

ROSEMBERG, J. M.

1995 Diccionario de administración y finanzas, Biblioteca Master Centrum, Barcelona.

SAMUELSON, Paul

1981 Curso de Economía Modema, Aguilar, Madrid.

\section{SIINTESIS}

1998 Las 5389 empresas líderes del Perú, Síntesis, Lima.

SCHLÜTER, Regina

1998 Investigación en turismo y hotelería, Centro de Investigación y Estudios Turísticos, Buenos Aires.

STONER, James; FREEMAN, Edward; GILBERT, Daniel

1996 Administración, Pretince-Hall Hispanoamericana, México.

TAYLOR, Frederick W.

1947 Scientific management. Harper and Brothers, New York.

ULRICH, Hans

1981 Principios de estrategia empresarial, EI Ateneo, Buenos Aires. 
VÁSQUEZH., Enrique

2000 Estrategias de poder: grupos económicos en el Perú. Centro de Investigación de la Universidad del Pacífico, Lima.

VOGELER, Carlos; HERNÁNDEZ, Enrique

1998 Estructura y Organización del Mercado Turístico, Ramón Areces, Madrid.
WEBB Richard; FERNÁNDEZ BACA, Graciela

2000 Anuario Estadístico Perú en Números 2000, Cuánto, Lima. 


\section{Anexo 1 \\ ASOCIACIONES Y GREMIOS DE TURISMO}

1. Asociación de Empresas de Transporte Aéreo Internacional (AETAl)

2. Asociación Femenina de Ejecutivas de Empresas Turísticas (AFEET)

3. Asociación de Guías de Montaña del Perú (AGMP)

4. Asociación de Guías Oficiales de Turismo (AGOTUR)

5. Asociación Peruana de Hoteles Restaurantes y Afines (AHORA)

6. Asociación Peruana de Agentes de Carga Internacional (APACIT)

7. Asociación Peruana de Albergues Turísticos Juveniles (APTAJ)

8. Asociación Peruana de Agencias de Viajes y Turismo (APAVIT)

9. Asociación Peruana de Operadores de Turismo Receptivo e Interno (APOTUR)

10. Asociación Peruana de Turismo de Aventura y Ecoturismo (APTAE)

11. Asociación Regional de Agencias de Viaje y Turismo Puno (ARAVIT)

12. Asociación Regional de Agencias de Viaje y Turismo Ancash (ARAVITA)

13. APAVIT - Chiclayo

14. APAVIT - San Martin

15. Asociación de Agentes de Viaje y Turismo de la Libertad

16. Asociación de Agencias de Viaje del Cusco

17. Asociación Turismo Club Internacional

18. American Society of Travel Agents INC. - Capítulo Perú (AVIT)

19. Asociación de Agentes de Viajes de Arequipa (AVIT)

20. Organización de Apoyo al Desarrollo Turístico (AYNI)

21. Cámara Hotelera Cusco

22. Cámara Nacional de Turismo (CANATUR)

23. Cámara Regional de Turismo de San Martín (CARETUR)

24. Cámara Regional de Turismo del Cusco (CARTUC)

25. Centro de Formación Turística (CENFORTUR)

26. Central de Información y Promoción Turística (CIPT)

27. Centro Europeo de Información y Promoción para América Latina (CEIPAL)

28. Centro Internacional de Difusión Turística

29. Sociedad Nacional de Turismo (CEVATUR-PERÚ / SONATUR)

30. Confederación Americana de Prensa Turística (CLAPTUR)

31. Colegio de Licenciados en Turismo del Perú

32. Comisión Consultiva de Derecho Aeronáutico Colegio de Abogados de Lima

33. Comisión Consultiva de Legislación de Turismo

34. Comité VISIT USA

35. Corporación Peruana de Aeropuertos y Aviación Comercial (CORPAC)

36. Grupo Pro Imagen Perú

37. IATA Sucursal Perú

38. Organización Iberoamericana de Investigación y Desarrollo Turístico

39. Asociación de la Prensa Turística del Perú (PRENSATUR)

40. Touring y Automóvil Club del Perú 


\section{Anexo 2}

INVERSIÓN EXTRANJERA POR SECTORES: AÑOS 1990-1999

(Millones de dólares)

\begin{tabular}{|c|c|c|c|c|c|c|c|c|c|c|}
\hline Sector/Año & 1990 & 1991 & 1992 & 1993 & 1994 & 1995 & 1996 & 1997 & 1998 & 1999 \\
\hline Comunicación & 0.01 & 0.01 & 0.01 & 0.10 & $2,003.00$ & $2,005.00$ & $2,007.00$ & $2,060.00$ & $2,099.00$ & $2,153.00$ \\
\hline Energia & 1.00 & 1.00 & 3.00 & 3.00 & 365.00 & 853.00 & 749.00 & 1.281 .00 & $1,375.00$ & $1,439.00$ \\
\hline Mineria & 42900 & 437.00 & 557.00 & 565.00 & 876.00 & 1.045 .00 & $1,140.00$ & $1,219.00$ & $1,364.00$ & $1,649.00$ \\
\hline Industria & 440.00 & 455.00 & 46500 & 515.00 & 568.00 & 706.00 & $1,035.00$ & $1,244.00$ & $1,362.00$ & $1,380,00$ \\
\hline Finanzas & 102.00 & 107.00 & 13500 & 191.00 & 235.00 & 501.00 & 685.00 & 767.00 & 90200 & 1,02200 \\
\hline Petróleo & 59.00 & 59.00 & 59.00 & 59.00 & 59.00 & 61.00 & 94.00 & 104.00 & 135.00 & 140.00 \\
\hline Turismo & 10.00 & 10.00 & 1200 & 1200 & 19.00 & 26.00 & 37.00 & 37.00 & 4200 & 4200 \\
\hline Agricultura & 4.00 & 4.00 & 5.00 & 5.00 & 5.00 & 8.00 & 7.00 & 8.00 & 25.00 & 40.00 \\
\hline Otros & 263.00 & 262.00 & 267.00 & 288.00 & 319.00 & $341 . \infty 0$ & 476.00 & 550.00 & 654.00 & 707.00 \\
\hline TOTAL & $1,308.01$ & $1,335.01$ & $1,503.01$ & $1,638.10$ & $4,449.00$ & $5,546.00$ & $6,230.00$ & $7,270.00$ & $7,958.00$ & 8,57200 \\
\hline
\end{tabular}

Fuente: CONITE

Elaboracion: BADATUR-EPTH

Anexo 3

VOLUMEN E IMPORTANCIA RELATIVA DE LAS 1000 PRIMERAS EMPRESAS, SEGÚN ACTIVIDAD ECONÓMICA, 1998

(Miles de nuevos soles)

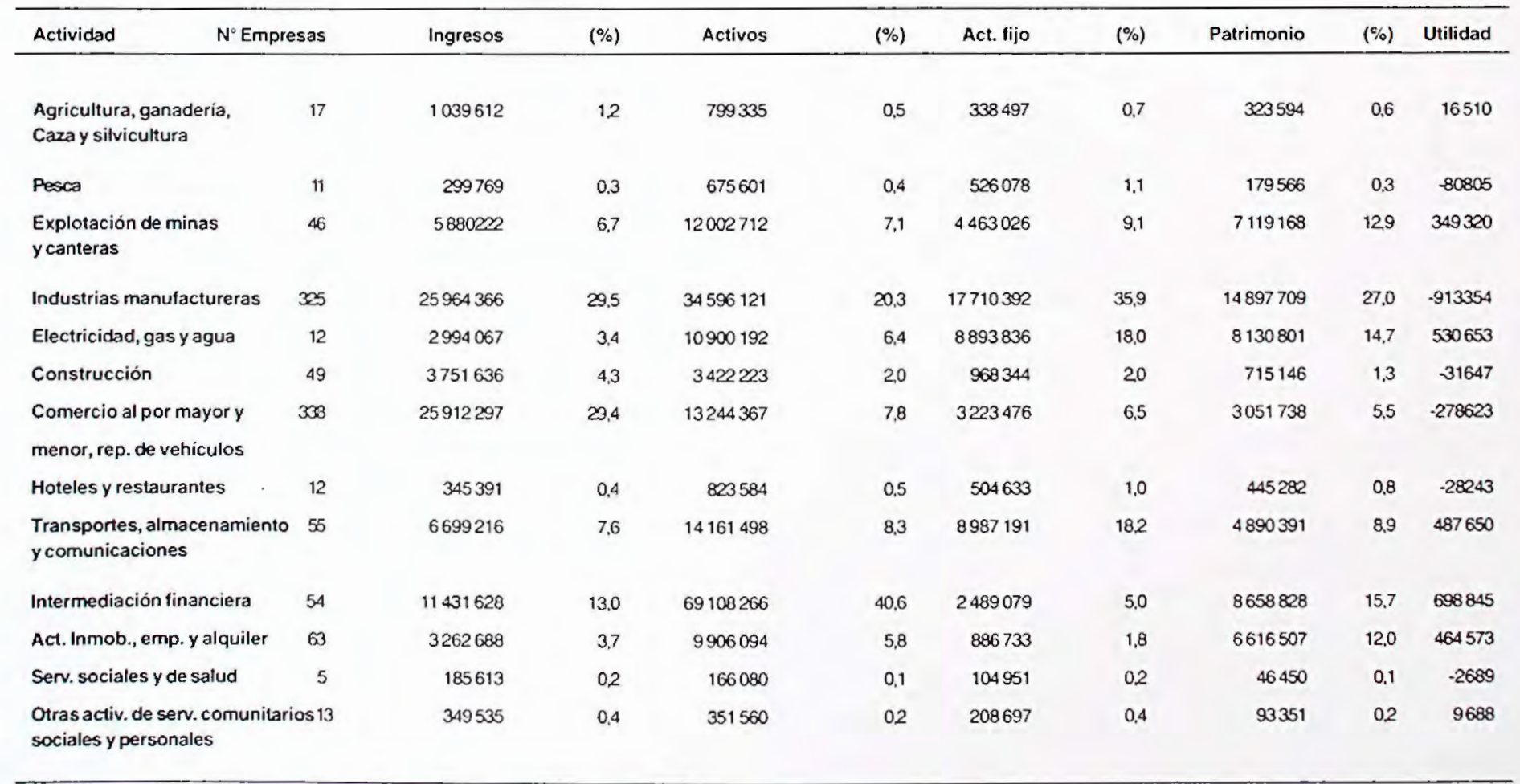

Fuente: CONASEV/Webb, R.; Femandez Baca, G., Peru en Números 2000.

Elaboración: Propia 
Anexo 4

HOTELES Y APART HOTEL DE 4 Y 5 ESTRELLAS, 1999

\begin{tabular}{|c|c|c|c|c|c|}
\hline Establecimiento & Clase & Categ. & Hab. & Camas & Ciudad \\
\hline TOTAL & & & 4495 & 7055 & \\
\hline 1 Hotel Crillón & Hotel & 5 & 305 & 530 & Lima \\
\hline 2 Lima Sheraton Hotel \& Towers & Hotel & 5 & 457 & 796 & Lima \\
\hline 3 El Pardo Hotel & Hotel & 5 & 9 & 172 & Lima \\
\hline 4 Hotel Las Américas & Hotel & 5 & 177 & 287 & Lima \\
\hline 5 Miraflores Cesar' S Hotel & Hotel & 5 & 150 & 354 & Lima \\
\hline 6 Miraflores Park Plaza & Hotel & 5 & 81 & 81 & Lima \\
\hline 7 Bruce & Hotel & 5 & 56 & 102 & Lima \\
\hline 8 Country Club de Lima & Hotel & 5 & 76 & 77 & Lima \\
\hline 9 Hotel El Olivar & Hotel & 5 & 134 & 154 & Lima \\
\hline 10 Swiss Hotel - Lima & Hotel & 5 & 244 & 488 & Lima \\
\hline 11 Hotel Los Delfines & Hotel & 5 & 206 & 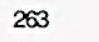 & Lima \\
\hline 12 Monasterio & Hotel & 5 & 122 & 197 & Cusco \\
\hline 13 Libertador Cusco & Hotel & 5 & 131 & 264 & Cusco \\
\hline 14 Libertador Arequipa & Hotel & 5 & 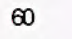 & 126 & Arequipa \\
\hline 15 Gran Hotel El Golf Trujillo & Hotel & 5 & 118 & 202 & Trujillo \\
\hline 16 Apart Hotel Las Américas & Apart Hotel & 5 & 64 & 68 & Lima \\
\hline 17 Sol de Oro Apart Hotel & Apart Hotel & 5 & 74 & 74 & Lima \\
\hline 18 El Condado Apart Hotel & Apart Hotel & 5 & 29 & 29 & Lima \\
\hline 19 Del Pilar Apart Hotel & Apart Hotel & 5 & 96 & 165 & Lima \\
\hline 20 Suites Hotel San Isidro & Apart Hotel & 5 & 54 & 72 & Lima \\
\hline 21 Royal Park Hotel \& Suites & Apart Hotel & 5 & 87 & 87 & Lima \\
\hline 22 Los Tallanes Hotel \& Suites & Apart Hotel & 5 & 44 & 44 & Lima \\
\hline 23 Las Palmeras de San Isidro & Apart Hotel & 5 & 42 & 42 & Lima \\
\hline 24 Golf Los Incas & Apart Hotel & 5 & 89 & 93 & Lima \\
\hline 25 ElPolo & Apart Hotel & 5 & 31 & $\approx$ & Lima \\
\hline 26 Maria Angola & Hotel & 4 & 58 & 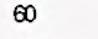 & Lima \\
\hline 27 El Condado Miraflores Hotel & Hotel & 4 & 58 & 114 & Lima \\
\hline 28 Jose Antonio & Hotel & 4 & 84 & $9 \mathbb{R}$ & Lima \\
\hline 29 La Hacienda Hotel & Hotel & 4 & 57 & 96 & Lima \\
\hline 30 Turismo Boulevard S.A. & Hotel & 4 & 65 & 125 & Lima \\
\hline 31 Grand Hotel Miraflores & Hotel & 4 & 48 & 92 & Lima \\
\hline 32 Palace & Hotel & 4 & 47 & $\infty$ & Lima \\
\hline 33 Jose Antonio Executive & Hotel & 4 & 40 & 76 & Lima \\
\hline 34 Del Pilar Miraflores Hotel & Hotel & 4 & 53 & 73 & Lima \\
\hline 35 Libertador Lima & Hotel & 4 & 52 & 100 & Lima \\
\hline 36 Garden Hotel & Hotel & 4 & 56 & 96 & Lima \\
\hline 37 Prince Hotel & Hotel & 4 & 51 & 81 & Lima \\
\hline 38 Hotel Riviera & Hotel & 4 & 158 & 216 & Lima \\
\hline 39 Gran Hotel Chiclayo & Hotel & 4 & 129 & 22 & Chiclayo \\
\hline 40 ElGran Marqués & Hotel & 4 & 46 & 86 & Trujilio \\
\hline 41 Laguna Seca & Hotel & 4 & 41 & 74 & Cajamarc \\
\hline 42 Libertador/Trujillo & Hotel & 4 & 78 & 141 & Trujillo \\
\hline 43 Mossone & Hotel & 4 & 100 & 215 & Ica \\
\hline 44 Pontal Hotel & Hotel & 4 & 58 & 108 & Arequipa \\
\hline 45 Apart Hotel Las Suites & Apart Hotel & 4 & 28 & 28 & Lima \\
\hline 46 Residencial Las Américas & Apart Hotel & 4 & 45 & 45 & Lima \\
\hline 47 Roosevelt Hotel \& Suites & Apart Hotel & 4 & 24 & 24 & Lima \\
\hline
\end{tabular}

Fuente: MITINCI/Webb, R.; Femandez Baca, G., Perú en Números 2000

Elaboración: propia 
Anexo 5

RANKING DE LAS EMPRESAS LÍDERES 1999: TRANSPORTE (*)

\begin{tabular}{|c|c|c|c|c|c|c|}
\hline $\begin{array}{l}\text { Ranking } \\
1999\end{array}$ & Razón Social & $\begin{array}{l}\text { Utilidad/Pérdida } \\
\text { (Miles de soles) }\end{array}$ & $\begin{array}{l}\text { Activo Total } \\
\text { (Miles de soles) }\end{array}$ & $\begin{array}{l}\text { Activo Fijo } \\
\text { (Miles de soles) }\end{array}$ & $\begin{array}{l}\text { Patrimonio } \\
\text { (Miles de soles) }\end{array}$ & $\begin{array}{l}\text { Ingresos Total } \\
\text { (Miles de soles) }\end{array}$ \\
\hline 47 & AEROCONTINENTES.A. & $-2,595$ & 87,450 & 6,265 & 8,267 & 347,455 \\
\hline 219 & IBERIA LINEAS AEREAS DE ESPAÑA S.A. & $-8,651$ & 4,170 & 1,062 & $-37,558$ & 85.919 \\
\hline 256 & EXPRESO CRUZ DEL SUR DEL PERU S.A. & -928 & 114,717 & 92027 & 26,428 & 74,397 \\
\hline 263 & KLM HOLANDESA DE AVIACION & 46,946 & 5,911 & 1,549 & $3,7 \oplus$ & 72,006 \\
\hline 362 & UNITED AIRLINES INC & $-4,218$ & 3,204 & 1,705 & $-13,373$ & 49,505 \\
\hline 452 & EXPRESO INTERNACIONAL ORMEÑOS.A. & 3.015 & 113,349 & 56,631 & 25,275 & 40,129 \\
\hline 458 & AEROLINEAS ARGENTINAS S.A. & 13,254 & 4,711 & 54 & 3,890 & 39,732 \\
\hline 584 & DELTA AIRLINES INC & 2,537 & 2,947 & 1,204 & -645 & 30,372 \\
\hline 617 & LANPERU S.A. & $-11,298$ & 30,001 & 3,866 & $-8,203$ & 28,609 \\
\hline$\notin 27$ & SOYUZS.A. & 2,839 & 27,226 & 21,211 & 9,736 & 27,881 \\
\hline$€ 31$ & AEROCONDORS.A.C. & $-1,427$ & 51,351 & 26,149 & 7,751 & 27,708 \\
\hline 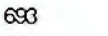 & LUFTHANSA LINEAS AEREAS ALEMANAS & -811 & 513 & 58 & 50 & 24,728 \\
\hline 922 & LLOYD AEREO BOLIVIANOS.A. & 4,499 & 1,878 & 444 & 244 & 16,739 \\
\hline 962 & AEREO TRANSPORTE S.A. ATSA & -445 & 32,602 & 22788 & 3.947 & 15,779 \\
\hline 968 & VARIGS.A. & -3.532 & 2,125 & 20 & 1.522 & 15,722 \\
\hline 1219 & CHALLENGE AIR CARGOINC & 6,053 & 6,627 & 709 & 6,079 & 11,327 \\
\hline 1377 & SERVICIOS AVENSA S.A. & -250 & 2,425 & 1 & $-11,474$ & 9,406 \\
\hline 1587 & HELICOPTEROS DEL SURS.A. & -372 & 9,925 & 5,564 & 3.635 & 6.581 \\
\hline 1597 & TRANSPORTES OLANOS.A. & -119 & 4,252 & 3,424 & 3 & 6.441 \\
\hline 1605 & EMPRESA DE TRANSPORTE ATAHUALPA & 4 & 9,488 & 7,920 & 2,465 & 62207 \\
\hline 1663 & EMP. DE TRANS MCAL. CACERES S.A. & $-2,911$ & 14,467 & 11,544 & 3,916 & 5,141 \\
\hline 1674 & EMP. DE TRANS. EL DORADO S.A.C. & 942 & 5,204 & 4,457 & 2,203 & 4,985 \\
\hline 1738 & AUTAUA & 1,763 & 1,843 & 0 & 2 & 3.681 \\
\hline 2056 & AMERICAN AIRLINESINC & 0 & 13,510 & 9,834 & 1,934 & 0 \\
\hline
\end{tabular}

(") Ranking por ingresos entre las 2000 empresas lideres - datos 1999

Fuente: PERU MONITOR, LOS 2000 del 2000

Elaboración: BADATUR - EPTH

Anexo 6

RANKING DE LAS EMPRESAS LÍDERES 1999: HOTELES Y AGENCIAS DE VIAJE (*)

\begin{tabular}{|c|c|c|c|c|c|c|}
\hline $\begin{array}{l}\text { Ranking } \\
1999 \\
\end{array}$ & Ranking & $\begin{array}{l}\text { Ingresos Totales } \\
\text { (Miles de soles) }\end{array}$ & $\begin{array}{l}\text { Ingreso } \\
\text { (Miles d }\end{array}$ & $\begin{array}{l}\text { Ingresos Totales } \\
\text { (Miles de soles) }\end{array}$ & $\begin{array}{l}\text { Ingresos Totales } \\
\text { (Miles de soles) }\end{array}$ & $\begin{array}{l}\text { Utilidad/Pérdida } \\
\text { (Miles de soles) }\end{array}$ \\
\hline 390 & LIMA TOURSS.A. & 44467 & 19503 & 12818 & 8600 & 2799 \\
\hline 401 & HOTELES SHERATON DEL PERU S.A. & 44382 & 82797 & 64240 & 76425 & 4885 \\
\hline 447 & HOTELERA COSTA DEL PACIFICOS.A. & 44344 & 144854 & 135242 & 33308 & -10595 \\
\hline 470 & INVERS. NACIONALES DE TURISMO S A. INTURSA & 38364 & 102360 & 92963 & 53019 & 124 \\
\hline 535 & CONDOR TRAVEL S.A. & 33353 & 12300 & 4398 & 4505 & 1997 \\
\hline 544 & CORPORACION TURISTICA PERUANAS.A.C. & 32852 & 22344 & 14652 & 17858 & 11759 \\
\hline 591 & PROMOTORA DE TURISMO NUEVO MUNDO S.A. & 30008 & 13996 & 2920 & 2709 & 1327 \\
\hline 642 & INMOBILIARIA DE TURISMOS A. & 27201 & 99201 & 6241 & 3666 & -7337 \\
\hline 841 & PERU OEHS.A. & 19084 & 189663 & 5096 & 146704 & 15793 \\
\hline 852 & INVERSIONES MALECON DE LARESERVAS.A. & 18619 & 90305 & 74775 & 40231 & -483 \\
\hline 1012 & INVERSIONESEN TURISMOSA. & 14699 & 6382 & 59330 & 36586 & -8300 \\
\hline 1023 & SOLMARTOUR S.A. ORGANIZACION DE SERV. TURISTI. & 14547 & 1701 & 153 & 767 & 188 \\
\hline 1032 & INVERSIONESBRADE S.A. & 14282 & 32163 & 26301 & 19832 & .98 \\
\hline 1059 & GRAN TOUR PERUS.A. & 13373 & 3794 & 111 & 1975 & 1744 \\
\hline 1109 & DASA TOUR PERUS A. & 12917 & 1529 & 431 & 911 & $6 \infty 2$ \\
\hline 1138 & OPERADORA DE HOTELES LAS AMERICAS S.A. & 12570 & 6459 & 838 & 4699 & 3788 \\
\hline 1177 & COSTA MAR TRAVEL CRUISE \& TOURS S. A. & 11912 & 2264 & 507 & 560 & 206 \\
\hline 1316 & EXPLORANDESS.A. & 10198 & 3879 & 2661 & 384 & -19 \\
\hline 1367 & HOTEL LAPAZS.A. & 9481 & 60637 & 54150 & 17126 & -3778 \\
\hline 1420 & VIRACOCHA TURISMO INTEANACIONAL S.A. & 9035 & 805 & 73 & 325 & 228 \\
\hline 1582 & TURISMO LOS ALGARROBOSS.A. & 6680 & 14513 & 11553 & 3096 & 419 \\
\hline 1596 & APART HOTEL S.A. & 6461 & 33061 & 23338 & 7061 & -5070 \\
\hline 1607 & CORPORACION HOTELERA CAMINO REALS.A. & 6186 & 13645 & 10953 & -901 & -59 \\
\hline 1648 & CONSORCIO HOTELERO DEL NORTE S.A. & 5431 & 38050 & 32321 & 12634 & -1548 \\
\hline
\end{tabular}


(continuación)

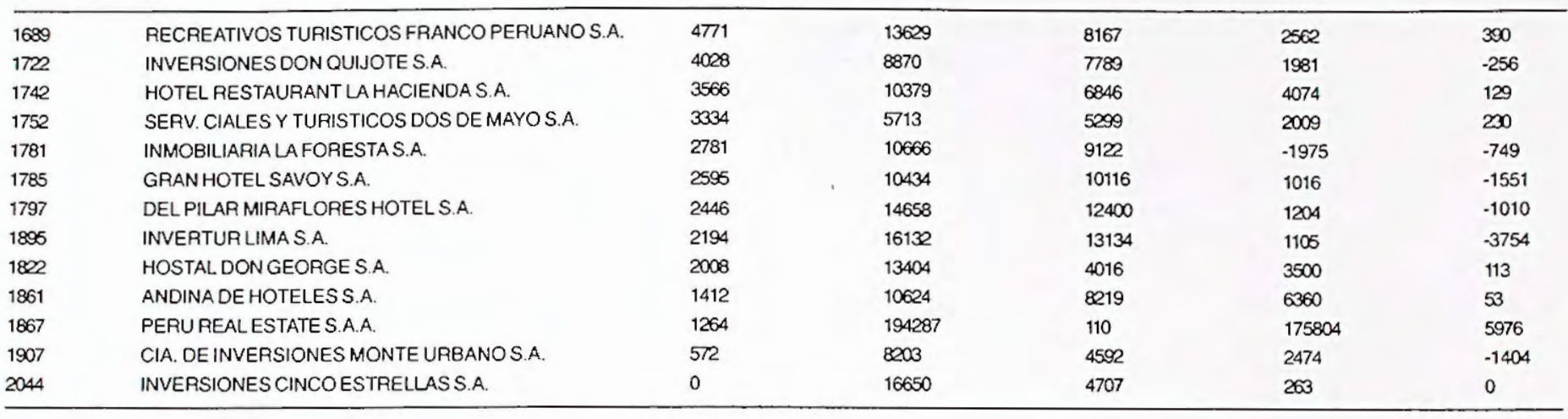

(*) Ranking por ingresos entre las 2000 empresas lideres - datos 1999

Fuente: PERU MONITOR. Los 2000 del 2000

Elaboración: BADATUR - EPTH

Anexo 7

RANKING DE LAS EMPRESAS LÍDERES 1999: RESTAURANTES (*)

\begin{tabular}{|c|c|c|c|c|c|c|}
\hline $\begin{array}{l}\text { Ranking } \\
1999\end{array}$ & Razón Social & $\begin{array}{l}\text { Ingresos total } \\
\text { (Miles de soles) }\end{array}$ & $\begin{array}{c}\text { Activo total } \\
\text { (Miles de soles) }\end{array}$ & $\begin{array}{c}\text { Activo fijo } \\
\text { (Miles de soles) }\end{array}$ & $\begin{array}{c}\text { Patrimonio } \\
\text { (Miles de soles) }\end{array}$ & $\begin{array}{l}\text { Utilidad/Pérdida } \\
\text { (Miles de soles) }\end{array}$ \\
\hline 459 & DELOSIS.A. & 39,717 & 26.208 & 11,226 & 10,257 & 748 \\
\hline 618 & BEMBOS S.A.C. & 28.600 & 24,646 & 15,600 & 4,887 & $-2,192$ \\
\hline 637 & COCINA DE VUELO OCAMPO & 27,500 & 16,159 & 3.543 & 9,192 & 5,193 \\
\hline 670 & SIGDELO S.A. & 26.213 & 22,502 & 10,455 & 8,629 & $-2,002$ \\
\hline 837 & SAIDEL S.A. & 19.212 & 16,600 & 11,866 & 11,725 & $-33,321$ \\
\hline 838 & PANADERIA SAN JORGE & 18,470 & 10,613 & 4,978 & 7,566 & 1,826 \\
\hline 902 & LARISA SA. & 16,599 & 12,344 & 7,258 & 2.399 & 763 \\
\hline 1399 & ROLLY'S PANADERÍA & 9.177 & 6,063 & 1,089 & 2.034 & 227 \\
\hline 1424 & GELATERIA LARITZA S.A. & 8,975 & 4,899 & 2.631 & $-1,384$ & .753 \\
\hline 1622 & REST.CHIFA LONG FONG S.A. & 5,917 & 4,131 & 3,239 & 406 & 136 \\
\hline
\end{tabular}

(") Ranking por ingresos entre las 2000 empresas lideres - datos 1999

Fuente: PERU MONITOR, Las 2000 del 2000

Elaboración: BADATUR - EPTH 


\section{Anexo 8}

RANKING DE LAS EMPRESAS LÍDERES 1996: RESTAURANTES (*)

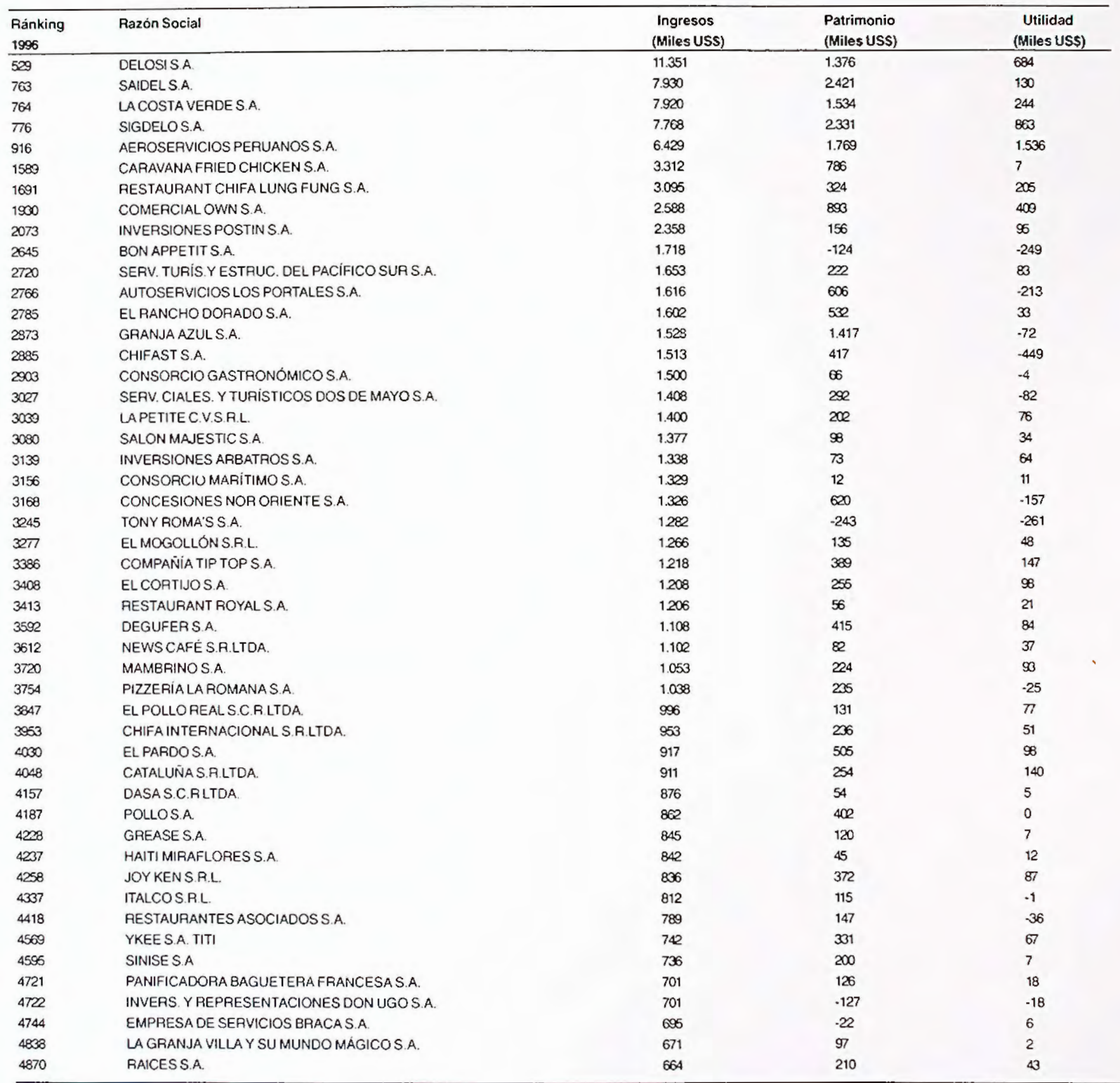

(•) Ranking por ingresos entre las 5389 empresas lideres - datos 1996

Fuente: Sintesis. Las 5389 empresas lideres del Peni.

Elaboración: Propia 